\title{
Abilities of Pre- and Postoperative High-Sensitivity C-Reactive Protein Levels to Predict 90-Day Mortality After Surgery for Abdominal and Thoracic Cancers
}

\author{
Tak Kyu Oh, MD and Jung-Hee Ryu, MD, PhD \\ Seoul National University Bundang Hospital, Seongnam, Korea
}

\section{PAST}

High-sensitivity C-reactive protein (hsCRP) is more sensitive to inflammatory reactions than CRP and initially was found to be useful for predicting cardiovascular risk. ${ }^{1}$ In addition, HsCRP is reported to be associated with cancer prognosis, and a recent study validated the ability of preoperative hsCRP to predict postoperative prognosis among cancer patients. ${ }^{2,3}$ However, data are inadequate regarding whether pre- or postoperative hsCRP levels have better predictive value after oncologic surgery.

\section{PRESENT}

In our study, ${ }^{4}$ both elevated pre- and postoperative hsCRP levels were associated with increased risks of 90-day mortality after surgery for thoracic and abdominal cancers. However, preoperative hsCRP had better prognostic value than postoperative hsCRP. Additionally, preoperative hsCRP had the best predictive value for lung and esophageal cancers, whereas postoperative hsCRP had the best predictive value for urologic cancer.

ASO Author Reflections offer a brief invited commentary on the article, "Abilities of Pre- and Postoperative High-Sensitivity C-Reactive Protein Levels to Predict 90-Day Mortality After Surgery for Abdominal and Thoracic Cancers." Ann Surg Oncol. 2018. https://doi.org/10.1245/s10434-018-6734-9.

(C) Society of Surgical Oncology 2018

First Received: 10 August 2018; Published Online: 30 August 2018

J.-H. Ryu, MD, PhD

e-mail: Jinaryu74@gmail.com

\section{FUTURE}

Although this study demonstrated the abilities of preand postoperative high-sensitivity $\mathrm{C}$-reactive protein levels to predict 90-day mortality after surgery for abdominal and thoracic cancers, it had some limitations due to the nature of its retrospective design. Therefore, prospective study should be performed to confirm the abilities of pre- and postoperative hsCRP levels to predict long-term mortality after surgery for cancers.

DISCLOSURE There are no conflicts of interest.

\section{REFERENCES}

1. Ridker PM. High-sensitivity C-reactive protein: potential adjunct for global risk assessment in the primary prevention of cardiovascular disease. Circulation. 2001;103:1813-8.

2. Casadei Gardini A, Carloni S, Scarpi E, et al. Prognostic role of serum concentrations of high-sensitivity C-reactive protein in patients with metastatic colorectal cancer: results from the ITACa trial. Oncotarget. 2016;7:10193-202.

3. Ko YJ, Kwon YM, Kim KH, et al. High-sensitivity C-reactive protein levels and cancer mortality. Cancer Epidemiol Biomarkers Prev. 2012;21:2076-86.

4. Oh TK, Choi YR, Oh AY, Chung SH, Han S, Ryu JH. Abilities of preoperative and postoperative high-sensitivity C-reactive protein levels to predict 90-day mortality after surgery for abdominal and thoracic cancers. Ann Surg Oncol. 2018. https://doi.org/10.1245/ s10434-018-6734-9. 